\title{
Intoxicação experimental por Callaeum psilophyllum em coelhos e caprinos
}

\section{Experimental poisoning by Callaeum psilophyllum in rabbits and goats}

\author{
Amélia Lizziane Leite Duarte ${ }^{1 *}$; Rosane Maria Trindade Medeiros ${ }^{1}$; \\ Fabrício Kleber de Lucena Carvalho ${ }^{1}$; Francelícia Pereira Marques Dantas ${ }^{1}$; \\ Anna Priscilla Moreira Figueiredo ${ }^{1}$; Franklin Riet-Correa ${ }^{2}$
}

\section{Resumo}

Callaeum (Mascagnia) psilophyllum é encontrada nas mesmas regiões que Amorimia (Mascagnia) rigida, uma planta que contêm monofluoroacetato de sódio e causa morte súbita associada ao exercício em ruminantes. Com o objetivo de determinar a toxicidade de C. psilophyllum, folhas desta planta foram administradas a coelhos e caprinos. Em coelhos, doses de 6-12 g. $\mathrm{kg}^{-1}$ de peso corporal causaram taquicardia, dispneia e midríase. Um coelho, que ingeriu $10 \mathrm{~g} . \mathrm{kg}^{-1}$, apresentou sinais clínicos semelhantes aos causados por $A$. rigida em coelhos. Em caprinos, quatro animais apresentaram diarreia após a ingestão de folhas verdes ou secas da planta. Três caprinos morreram e um se recuperou. Os resultados em coelhos sugerem que C. psilophyllum contêm fluoroacetato. No entanto, os sinais clínicos em caprinos sugerem que C. psilophyllum contêm outra substância responsável pelos sinais digestivos. Palavras-chave: Plantas tóxicas, Amorimia, Mascagnia, monofluoroacetato, diarreia

\begin{abstract}
Callaeum (Mascagnia) psilophyllum is found in the same regions than Amorimia (Mascagnia) rigida, a sodium monofluoroacetate containing plant that cause sudden death associated with exercise in ruminants. With the objective to determine the toxicity of C. psilophyllum, leaves of the plant were administered to rabbits and goats. In rabbits doses of 6-12 g. $\mathrm{kg}^{-1}$ body weight caused tachycardia, dyspnea, and mydriasis. One rabbit, that ingested $10 \mathrm{~g} / \mathrm{kg}$, showed clinical signs similar to those caused by $A$. rigida in rabbits. Four goats showed diarrhea after the ingestion of green or dry leaves of the plant. Three died and one recovered. The results in rabbits suggest that $C$. psilophyllum contains fluoroacetate. However, clinical signs in goats suggest that $C$. psilophyllum contains another substance responsible for the digestive signs.
\end{abstract}

Key words: Poisonous plants, Amorimia, Mascagnia, monofluoroacetate, diarrhea

Callaeum (Mascagnia) psilophyllum (Figuras 1A e B) da família Malpighiaceae é encontrada na região semiárida do Nordeste brasileiro onde também ocorre Amorimia (Mascagnia) rigida, planta que possui monofluoroacetato de sódio e causa morte súbita associada ao exercício (TOKARNIA; CANELLA;

\footnotetext{
${ }^{1}$ Discentes, Centro de Saúde e Tecnologia Rural, CSTR, Universidade Federal de Campina Grande, UFCG, Campus de Patos, Hospital Veterinário, 58700-000, Patos, PB. E-mail: lizzianeduarte@hotmail.com; rmtmed@uol.com.br; fabriciokleber@ hotmail.com; francedantas@hotmail.com; anna-moreira@hotmail.com

${ }^{2}$ Prof. do CSTR/UFCG, Campus de Patos, Hospital Veterinário, Patos, PB. E-mail: franklin.riet@pq.cnpq.br

* Autor para correspondência
} 
DOBEREINER, 1961; MEDEIROS et al., 2002). Atualmente, não se conhece a toxicidade de $C$. psilophyllum, porém, esta planta chamou a atenção pela semelhança com a $A$. rigida, tanto das folhas como dos frutos, e as duas plantas são encontradas nos mesmos locais e estas áreas geralmente são utilizadas para pastejo de ruminantes. Este trabalho teve como objetivo determinar a toxicidade de $C$. psilophyllum e seus efeitos tóxicos em coelhos e caprinos.

Nos experimentos em coelhos, folhas da planta foram coletadas, dessecadas e trituradas. As folhas assim preparadas foram administradas a seis coelhos adultos e hígidos, em doses únicas de 2, 4, 6, 8, 10 e 12 g.kg-1 de peso corporal. Para a administração as folhas moídas eram misturadas em água destilada na proporção de $10 \mathrm{~mL}$ de água para cada grama de folhas trituradas. O coelho era mantido em gaiola individual e submetido ao jejum alimentar e hídrico de 24 e 8 horas, respectivamente. A solução contendo C. psilophylum foi fornecida através de uma sonda orogástrica introduzida com auxílio de um abre-boca acoplado a uma seringa. Após a administração, o coelho era mantido em gaiola individual e aproximadamente a cada duas horas era estimulado a caminhar, durante um período de dois minutos com descanso de mais dois minutos. Esse procedimento foi repetido por cinco vezes e o coelho mantido na mesma gaiola e observado continuamente durante as 24 horas seguintes.

Figura 1. Callaeum psilophyllum da fazenda Cabeça de Porco, Município de Zabelê (PB), 14/09/2009. (A) folhas e flores; (B) frutos.

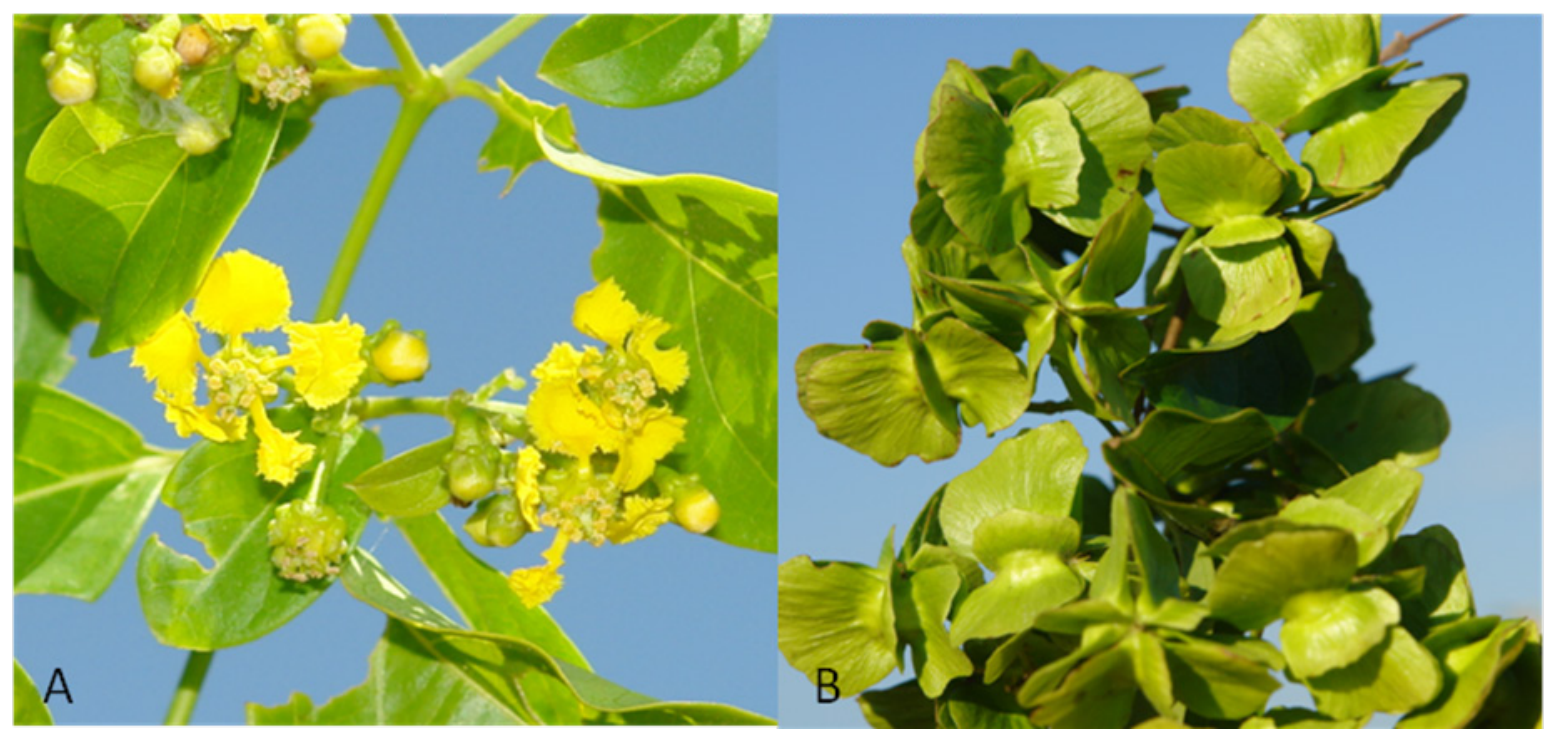

Fonte: Elaboração dos autores.

Doses de 2 e 4 g. $\mathrm{kg}^{-1}$ de solução com folhas de C. psilophylum não foram tóxicas, porém os coelhos que receberam doses de 6, 8, 10 ou 12 g.kg ${ }^{-1}$, apresentaram, após serem estimulados a caminhar, taquicardia, dispnéia e midríase, retornando ao estado fisiológico duas a três horas após. O coelho que recebeu dose de 10 g. $\mathrm{kg}^{-1}$, após
50 minutos de ingestão da solução, subitamente começou a fazer movimentos desordenados, corria em círculos dentro da gaiola e vocalizava, houve segunda manifestação desses sinais, cinco minutos após, e o animal morreu. Na necropsia, no coração havia áreas multifocais irregulares pálidas na base do ventrículo esquerdo. O fígado encontrava-se 
discretamente avermelhado e aumentado de volume, e ao corte fluía sangue. Os rins apresentavam superfície cortical avermelhada. Na histopatologia observou-se, no coração, presença de grupos musculares com eosinofilia citoplasmática e núcleos retraídos e hipercromáticos, característicos de necrose de fibras cardíacas. Alguns cardiomiocitos apresentavam também necrose individual e outros estavam vacuolizados, distribuídos aleatoriamente. No fígado observou-se congestão moderada e difusa com dilatação dos sinusoides e, ocasionalmente, necrose periportal. Os rins apresentavam áreas multifocais de congestão, na região córticomedular.

Para os experimentos com caprinos foram utilizados quatro animais; dois $(\mathrm{C} 1$ e $\mathrm{C} 2)$ receberam três doses diárias de $5 \mathrm{~g} \cdot \mathrm{kg}^{-1}$ de folhas verdes de C. psilophylum coletadas no mesmo local do experimento com coelhos. Os outros dois caprinos receberam folhas da mesma procedência, porém dessecadas: o $\mathrm{C} 3$ recebeu três doses diárias de $1,5 \mathrm{~g} \cdot \mathrm{kg}^{-1}$ e o $\mathrm{C} 4$ três doses diárias de $1 \mathrm{~g} \cdot \mathrm{kg}^{-1}$. As folhas verdes foram administradas diariamente, em dose única e em pequenas quantidades na boca do animal e a planta seca foi moída, diluída em água e fornecida através de sonda esofagiana.

Os caprinos $\mathrm{C} 1, \mathrm{C} 2$ e $\mathrm{C} 4$ apresentaram os primeiros sinais clínicos no terceiro dia de experimento e o C3 no segundo dia. Os sinais clínicos foram semelhantes nos quatro animais; inicialmente mostraram anorexia, fezes pastosas que posteriormente evoluíram para diarreia aquosa, perda de peso e relutância para se movimentar, seguida de decúbito com gemidos e salivação. Os caprinos $\mathrm{C} 1, \mathrm{C} 2$ e $\mathrm{C} 3$ foram a óbito no $5^{\circ}, 3^{\circ}$ e $6^{\circ}$ dia, respectivamente. $\mathrm{O} \mathrm{C} 4$ recuperou-se após ser tratado mediante transfaunação, administração de antidiarreicos (associação de fitalisulfatiazol, sulfamerazina, clortetraciclina, hidróxido de alumínio e silicato de alumínio) e aplicação de vitaminas e minerais (associação de cloreto de cobalto, sulfato de cobre, citrato de ferro amoniacal e vitamina B12).
$\mathrm{Na}$ necropsia de $\mathrm{C}$, , constatou-se presença de conteúdo hemorrágico ao longo do trato digestório, ulceração de aproximadamente $0,5 \mathrm{~cm}$ de diâmetro na mucosa do cárdia e leve avermelhamento na mucosa do omaso e do retículo. No abomaso, observou-se que conteúdo sanguinolento. Na histopatologia, na submucosa do rúmen observouse hiperemia acentuada. No omaso observaram-se áreas focais de necrose do epitélio; na submucosa havia restos celulares e infiltrado, moderado e multifocal, de células mononucleares. Áreas de hiperemia foram identificadas tanto na mucosa como na submucosa. No abomaso observou-se hiperemia, hemorragias e degeneração e necrose das criptas gástricas associadas à infiltração por neutrófilos, linfócitos, plasmócitos e macrófagos. $\mathrm{Na}$ submucosa abomasal, observou-se hiperemia dos vasos com presença de áreas focais de infiltrado inflamatório mononuclear. $\mathrm{Na}$ lâmina própria observava-se infiltrado inflamatório mononuclear moderado, multifocal a coalescente e hiperemia. $\mathrm{Na}$ submucosa havia hiperemia. No piloro notouse hiperemia com hemorragia das criptas gástricas e presença de focos leves de infiltrado inflamatório mononuclear, com áreas necróticas principalmente no topo das criptas associado a neutrófilos, restos celulares e agregados bacterianos. No duodeno observou-se necrose das criptas, hiperemia e hemorragias associados à infiltrado mononuclear multifocal a coalescente. No intestino grosso foram constatadas degeneração e necrose moderada das células epiteliais com atenuação e junção do epitélio associado à hiperemia difusa com áreas de hemorragia. No topo do epitélio observou-se presença de infiltrado inflamatório neutrofílico, restos celulares e agregados bacterianos. Havia necrose das glândulas de Lieberkuhn, muitas dessas com perda do epitélio e infiltrado inflamatório mononuclear difuso ou multifocal. O rim apresentava-se com hiperemia e hemorragia.

Lesões macroscópicas semelhantes as de $\mathrm{C} 1$ foram observadas em $\mathrm{C} 2$ em todos os órgãos, além de petéquias no coração com distribuição 
multifocal, principalmente na região dos sulcos paraconal e coronário. $\mathrm{Na}$ histopatologia as lesões foram semelhantes, às de $\mathrm{C} 1$, porém com menor intensidade.

Os principais achados macroscópicos observados em C3 consistiam na presença de linfonodos mesentéricos aumentados de volume, que, ao corte, apresentavam áreas pálidas entremeadas com áreas escuras e pontos avermelhados. Haviam áreas hemorrágicas na válvula íleo-cecal e mucosa do rúmen, retículo e omaso. As veias mesentéricas encontravam-se ingurgitadas, principalmente as localizadas no terço final do jejuno, onde também se observavam áreas avermelhadas na mucosa. $\mathrm{Na}$ histopatologia as lesões do abomaso, duodeno e intestino grosso foram semelhantes às observadas no $\mathrm{C} 1$. No retículo, observou-se infiltrado inflamatório mononuclear, multifocal e moderado, com presença em algumas áreas de focos de ulceração do epitélio, infiltrado inflamatório misto, hemorragia, restos celulares e agregados bacterianos.

Os sinais clínicos observados em coelhos, são semelhantes aos causados por $A$. rigida (TOKARNIA; DOBEREINER, CANELLA, 1987), e sugerem que Callaeum psilophyllum contêm monofluoroacetato de sódio. No entanto, os sinais digestivos apresentados pelos caprinos sugerem que, C. psilophyllum se consumida em condições naturais, não causaria morte súbita associada ao exercício. Em caprinos, os sinais clínicos sugerem que, além do monofluoroacetato de sódio, $C$. psilophyllum contêm, também, uma toxina que afeta o sistema digestório, que causa congestão e hemorragia ao longo deste, e se encontra tanto nas folhas verdes quanto nas dessecadas. No caso de ser consumida espontaneamente por ruminantes é provável que C. psilophyllum cause sinais digestivos, em lugar de morte súbita como é o caso de $A$. rigida.

\section{Referências}

MEDEIROS, R. M. T.; GERALDO NETO, S. A.; BARBOSA, R. C.; LIMA, E. F.; RIET-CORREA, F. Sudden bovine death from Mascagnia rigida in Northeastern Brazil. Veterinary and Human Toxicology, Manhattan, v. 44, n. 5, p. 286-288, 2002.

TOKARNIA, C.H.; CANELLA, C.F.C.; DOBEREINER, J. Intoxicação por um "tingui" (Mascagnia rigida Griseb.) em bovinos no Nordeste do Brasil. Arquivos do Instituto Biológico Animal, Rio de Janeiro, v. 4, p. 203 215, 1961.

TOKARNIA C. H.; DOBEREINER, J.; CANELLA, C. F. C. Intoxicação experimental por Mascagnia rigida (Malpighiaceae) em coelhos. Pesquisa Veterinária Brasileira, Seropédica, v. 7, n. 1, p. 11-16, 1987. 